\title{
DENIS BJAÏ, «Bonas litteras [juris] studiis admiscere» (Érasme). Les débuts de l'humanisme à Orléans
}

\section{Filippo Fassina}

\section{(2) OpenEdition}

\section{Journals}

\section{Edizione digitale}

URL: https://journals.openedition.org/studifrancesi/44873

DOI: 10.4000/studifrancesi.44873

ISSN: 2421-5856

\section{Editore}

Rosenberg \& Sellier

\section{Edizione cartacea}

Data di pubblicazione: 1 août 2021

Paginazione: $359-360$

ISSN: 0039-2944

\section{Notizia bibliografica digitale}

Filippo Fassina, «DENIS BJAï, «Bonas litteras [juris] studiis admiscere» (Érasme). Les débuts de l'humanisme à Orléans», Studi Francesi [Online], 194 (LXV | II) | 2021, online dal 01 septembre 2021, consultato il 15 octobre 2022. URL: http://journals.openedition.org/studifrancesi/44873 ; DOI: https://doi.org/10.4000/ studifrancesi. 44873

Questo documento è stato generato automaticamente il 15 octobre 2022

\section{(c) (i) (9)}

Creative Commons - Attribuzione - Non commerciale - Non opere derivate 4.0 Internazionale - CC BY NC-ND 4.0

https://creativecommons.org/licenses/by-nc-nd/4.0/ 


\title{
DENIS BJAÏ, «Bonas litteras [juris] studiis admiscere» (Érasme). Les débuts de l'humanisme à Orléans
}

\author{
Filippo Fassina
}

\section{NOTIZIA}

DENIS BJAÏ, «Bonas litteras [juris] studiis admiscere» (Érasme). Les débuts de l'humanisme à

Orléans, "Bibliothèque d'Humanisme et Renaissance" 2, LXXXI (2020), pp. 217-241.

1 Tra la fine del xv secolo e l'inizio del xvı, a Orléans, si verifica un interessante fenomeno di rinnovamento dell'insegnamento accademico, dovuto principalmente alla presenza di tre figure importanti del panorama letterario e culturale francese: Jean Reuchlin, Guillaume Budé ed Erasmo. L'A. prima analizza brevemente la figura di Reuchlin (il cui nome grecizzato è Capnion), ebraista, cabalista e grecista che soggiorna a Orléans nel 1479 e diventa docente di greco per i giovani nobili. Per quanto concerne, invece, Budé, vengono ricostruite alcune tappe della sua permanenza a Orléans nel 1483: viene sottolineato come questi abbia inizialmente abbandonato lo studio del diritto a causa dell'ambiente universitario, in cui l'insegnamento era impregnato di dogmatismo e si utilizzava un latino impuro e definito 'barbaro'. Solo nel 1491, grazie all'amicizia con François Deloynes, egli avrebbe potuto dedicarsi in maniera costante e approfondita allo studio del diritto e, soprattutto, della lingua greca. Il presente contributo si concentra, però, principalmente sull'esperienza vissuta da Erasmo presso la città di Orléans. Sembra infatti che l'umanista vi si sia recato almeno in due occasioni: nel 1500 per poco più di due mesi e nel 1506 per alcuni giorni. Se la seconda è solo una tappa del suo viaggio verso l'Italia, tappa consacrata a una breve visita all'amico Nicole Bérault; la prima è senza dubbio la più interessante. Erasmo avrebbe infatti lasciato Parigi per sfuggire a un'epidemia di peste o di influenza e avrebbe soggiornato presso Jacques Voecht (detto Tutor), maitre ès arts e futuro dedicatario dell'edizione erasmiana del De 
officis di Cicerone. L'A. sottolinea come, durante questo periodo di esilio forzato, Erasmo abbia continuato a lavorare alle sue opere, in particolare a trattati e manuali di epistolografia, retorica e latino, ma si sia dedicato soprattutto all'apprendimento della lingua greca biblica, patristica e classica. Erasmo avrebbe anche frequentato gli ambienti universitari, legandosi di un'amicizia particolare con Jean-Pyrrhus d'Angleberme. Infine, vengono citati altri eruditi che hanno contribuito, con la loro presenza, a rivitalizzare il contesto culturale di Orléans: in particolare François Tissard e soprattutto il grecista Girolamo Aleandro (Jérôme Aléandre), il cui rapporto con Erasmo passò da un'intima amicizia a una netta rivalità, per ragioni religiose. La presenza di questi intellettuali dimostra come attorno all'Università di Orléans si fosse sviluppato un vero e proprio milieu culturale e letterario, tappa fondamentale per l'evoluzione dell'Umanesimo in Francia. 